\title{
Work Attitudes in Transition: Some Implications for Management of Organizational Change in Bulgaria*
}

\author{
Snejana Ilieva**
}

The article deals with the peculiarities of work attitudes in conditions of transition to market economy. Dynamics of work attitudes are traced in a seven-year period - 1990-1997. It is shown how work attitudes could be described right after the fall of the socialist system, that means at beginning of the transition from planned to market economy and what changes in work attitudes occur under the influence of the difficult transition to market economy. A practical consequence of the study is that organizational change will not be effective if carried out in a random and unpredictable way, without consideration of people's values and attitudes. From this viewpoint the implementation of new approaches of human resource management is a requirement for the success of change, as well as for organizational efficiency.

Der Artikel befaßt sich mit den Besonderheiten von Arbeitseinstellungen unter den Bedingungen der Transformation von Plan zum Markt. Dazu werden über eine Periode von sieben Jahren (1990-1997) die Dynamiken von Arbeitseinstellungen nachgezeichnet. Es wird ein Verständnis darüber vermittelt, wie sich Arbeitseinstellungen am Beginn der Transformation von einer Plan- zur Marktwirtschaft darstellen. Weiterhin werden die Veränderungen in den Einstellungen zur Arbeit aufgezeigt, die sich aufgrund des schwierigen Transformationsprozesses ergeben Eine praktische Konsequenz die sich aus den Untersuchungen ergibt ist, daß organisationaler Wandel nur erfolgreich ist, wenn er geplant und unter Berücksichtigung der Werte und Einstellungen der Mitarbeiter durchgeführt wird. Aus dieser Sicht ist die Implementation neuer HRM-Ansätze für einen erfolgreichen Wandel notwendig

\footnotetext{
* manuscript received: 20.11.1998, accepted: 26.4.1999

** Ilieva, Snejana, PhD, (b.: 1960), Department of Social, Work, and Educational

Psychology, Sofia University "St. Kliment Ohridski", Sofia, Bulgaria, Main reseach topics: Organizational Development and Change, Organizational Culture, Leadership
} 


\section{Introduction}

Political, economic and social changes since 1989 set unfamiliar challenges to organizations in Bulgaria. They have been faced with the necessity of carrying out a transition from closed to open system, of restructuring and of creating market oriented organizational culture, which to take into consideration competitors' possibilities, as well as clients' and consumers' needs. Thus, the transition from planned to market economy is characterized by complete transformation of organizations and by deep changes in their strategies, structure and culture.

The past years from the beginning of the transition in Bulgaria however, show that organizational transformation is far from being realized in accordance to the prognoses and expectations.

Management of organizational change turned out to be a complex and long process, requiring knowledge, skills and experience from the Bulgarian managers. In most cases their idea for change is limited only to changes in strategy, objectives, structure, i.e. the "hard sides" of the organization. The significance of the "human side" in organization in the process of change is still underestimated. The fact that organizational change is a way of life, a continuous process, directed to improvement of efficiency, as well as to increase of people's satisfaction and psychological well-being, is not considered.

In personal aspect organizational change leads to crisis in work values and attitudes, which is expressed in giving a new meaning to the role of work and organization. These changes need new attitudes and behaviors to be developed. Organizational change is impossible, unless organizations succeed to motivate and engage their members and to make sense of their work life.

The present study aims at establishing the peculiarities of work attitudes in conditions of transition to market economy. Dynamics of work attitudes is traced in a seven-year period - 1990-1997. The first stage marks the beginning of the transition from planned to market economy and the data from this period give idea about work attitudes right after the fall of the socialist system. The second stage reveals what changes in work attitudes occur under the influence of the difficult transition to market economy.

\section{Theoretical Background}

Values and attitudes direct and predict work behavior. Unlike values, which are relatively stable and slightly susceptible to changes, attitudes respond comparatively fast to changes in social environment. Change in work attitudes is a result of the total economic and social change. Therefore, in conditions of crisis and transition from one form of social system to another attitudes are 
those behavior determinants, which reflect the direct influence of the situation.

In the last 15-20 years the view that people's work behavior is determined and predicted by work satisfaction, job involvement and organizational commitment, becomes more and more popular. These attitudes can be considered as acting in close interaction in a system, which reveals the affective reactions of personality to the whole work situation, as well as to some of its specific aspects.

Organizational commitment has been of long standing interest to researchers due to its demonstrated linkage to job performance, job tenure, absenteeism, turnover and tardiness (Mowday, Porter \& Steers, 1982). Organizational commitment has been defined in a variety of different ways. The concept has often been viewed as an affective response (attitude) resulting from an evaluation of the work situation which links or attaches the individual to the organization. Following the work of Porter et al. (1974) it is defined as "the relative strength of an individual's identification with, and involvement in, a particular organization". Conceptually, it can be characterized by at least three factors: (a) a strong belief in, and acceptance of, the organizational goals and values; (b) a willingness to exert considerable effort on behalf of the organization; and (c) a strong desire to maintain membership in the organization" (p.604).

A quite different view on organizational commitment known as the "side-bet theory" evolved from the work of Becker (1960), who regarded commitment as behavioral rather that attitudinal. According to this view, the individual is bound to the organization through extraneous interests (e.g., pensions, seniority) rather than a favorable affect toward the organization. The essential element here is that these investments on side-bets have cost or forfeiture implications that reduce the individual's options. Thus, from this perspective, commitment is the degree to which individuals become attached to an organization as a result of investment (time, effort, identification, rewards, etc.), as reflected in their intent to stay in the organization. Investments serve to increase commitment by increasing the costs of leaving the organization.

The normative approach, on the other hand, views organizational commitment as the totality of internalized normative pressures to act in a way that meets organizational interests. As such, the major determinants of commitment are the values, norms and beliefs that member hold, rather than the immediate utilitarian considerations of costs and benefits (Wiener, 1982).

Meyer and Allen (1990) suggested that these views have been confounded in the preceding studies. They integrated the existent notions about the nature of organizational commitment and defined it as a complex multidimensional construct with affective, continuance and normative components. 
Work satisfaction is an affective positive state, which is a result of the evaluation of the whole work situation (Locke, 1976). The basic aspects of work, contributing to high satisfaction, are included in five groups: the job content, the payment, the promotion and career development, the relationships with colleagues and with supervision (Smith, Kendall, Hulin, 1968).

Work satisfaction refers to the specific work situation, whereas commitment is more global concept, because it refers to the attitude to the organization as a whole. Hence organizational commitment is more stable, continuance attitude, oriented mainly towards future and the intention to stay in the organization (Locke, 1976; Mowday et al., 1982; Mottaz, 1987).

Job involvement is a construct that reflects the degree to which individuals identify with their jobs and regard them as important to their lives and central to their self-conceptions. The notion of involvement, in this study, is conceptualized as having two components: (a) the degree to which an individual is involved in a particular job and actively participates in it, and (b) a psychological state of identification with work in general, compared to other activities (e.g., family, leisure), that is, the importance of work in the person's total self-image (Lodahl \& Kejner, 1965; Rabinobitz \& Hall, 1977; Kanungo, 1982).

Work attitudes are result of the degree the work situation satisfies individual needs. Organizational commitment, job involvement and work satisfaction vary in profession, age, sex and tenure, but they also change in time in a certain generation. They react to the slightest social and economic changes comparatively faster than personality values and beliefs. This change from one side shows the declinations in work ethics and work alienation, and from the other can lead to new meaning of work in human life.

That is why the dynamics of work attitudes is of great importance for explanation of the ways in which social and in particular organizational change effects work behavior. To establish the dynamics of work attitudes, changes in them in a seven-year period were registered. The first study was conducted in 1990, and the second - in 1997. This period is long enough for development or decrease in work attitudes and hence in work moral and in work behavior to set in.

Since complex influences of environment are difficult to establish and measure, social, economic and political change is regarded as a background, on which concrete changes in work attitudes occur. From the beginning of 90s to present serious changes in social status and quality of life have happened. Unemployment increase, worsened economic conditions, inflation rise, failure of structural reform, lack of effectively working industry, privatization, lack of foreign investments and currency board are all events that directly or 
indirectly effect the psychological well-being of personality, as well as its work attitudes.

In 1990 work attitudes reflected the direct influence of socialist value system. In the second half of the decade it can be expected that the myth about the communist attitude towards work as a basic life need is totally destroyed. Failures in economic area from one side, and consequences of crisis in work motivation in the late socialism from the other, strongly influence work attitudes.

If Kurt Lewin's views about personality and social change are applied, the existence three periods in the process of change in values, attitudes, beliefs and behavior of personality should be considered (Lewin, 1951). The first phase is so called unfreezing, in which present beliefs, attitudes and standards of behavior are doubted. The second stage is the real change, when new views are beginning to be accepted and learned, values and attitudes acquire new content, and behavior is structured in accordance to this new content. During the third phase the newly accepted attitudes and behavior are put into practice.

In a situation of change demotivation and alienation of work is possible, as well as deep changes in work attitudes. These changes are not the real change, but rather the beginning of the change in attitudes. That is a period of vanishing of the old attitude toward work. Hence the work attitudes dynamics would be expressed rather in decrease, than in increase of their intensity. Parallel to the process of destroying of work values and attitudes, inherited from the socialist past, new attitudes towards work and organization appear.

At the same time changes in different attitudes do not pass simultaneously some react more flexibly, whereas others are slightly susceptible to influences of environment. That is determined by the peculiarities of each of the work attitudes and is expressed in particular dynamics, which they have in time. Environmental factors impact the fast changes in work satisfaction. Commitment is more stable attitude than work satisfaction and consequently it would change more slowly and in a longer period of time. Comparatively slight changes are expected in job involvement - it is the most rigid attitude, because it is closest to personality values and reveals directly the centrality of work in human life.

\section{Methods}

\section{Sample}

Data were obtained in 1990 from a sample of 392 full-time employees and in 1997 from a sample of 345 employees, working in different types of state organizations. The subjects were divided into groups according to their sex, age, profession and type of organization. 


\section{Measures}

Organizational commitment was measured by a 24-item instrument developed by Meyer and Allen (1990), which consisted of three subscales: Continuance, Affective and Normative commitment. Using a 5-point Likert-type format, the response categories for each item ranged from "strongly agree" to "strongly disagree". Validity was assessed by factor analysis, which yielded five distinct factors, i.e. Value of membership, Affective attachment, Intention to stay, Loyalty, Personal sacrifices of withdrawal. These factors confirm the multidimensionality of organizational commitment (see Angle \& Perry, 1981; Buchanan, 1974; McGee \& Ford, 1987; Meyer, Allen \& Gellalty, 1990).

Job involvement. The job involvement questionnaire used in this study was the 10-item scale constructed by Kanungo (1982). Each item had a 5-point scale ranging from "strongly agree" to "strongly disagree". As for the validity, a factor analysis revealed that job involvement comprised two dimensions: Identification with a particular job, and Ego-involvement in work.

Work satisfaction was measured by a 16-item scale, developed after an extensive literature review. Differentiation of satisfaction factors is generally accepted (Smith, Kendall, Hulin, 1969; Locke, 1976) and therefore, we use the traditional scheme for their determination. The following aspects of satisfaction are measure: satisfaction of work content, of working conditions, of colleagues, of supervision, of payment and overall work satisfaction. A 5point scale, where answers range from "strongly agree" to "strongly disagree", is used.

\section{Results and Discussions}

One-way ANOVA is used to establish significant effect of time period on studied dependant variables. Thus, not only time changes in organizational commitment, job involvement and work satisfaction are measured, but also statistical significance of differences is established.

\section{Changes in organizational commitment}

As shown in Table 1, significant differences in all components of organizational commitment in time are observed. Changes in affective attachment, loyalty and intention to stay are essentially big.

Table 1. Changes in organizational commitment (means and F)

\begin{tabular}{|c|c|c|c|}
\hline $\begin{array}{c}\text { Organizational } \\
\text { Commitment }\end{array}$ & $\begin{array}{c}\bar{x}_{\mathbf{1}^{-}} \\
\mathbf{1 9 9 0}\end{array}$ & $\begin{array}{c}\bar{x}_{2}- \\
\mathbf{1 9 9 7}\end{array}$ & F \\
\hline Membership value & 4.02 & 3.49 & $31.50 ; \mathrm{p}<0.001$ \\
\hline
\end{tabular}




\begin{tabular}{|l|l|l|l|}
\hline Affective attachment & 4.38 & 3.33 & $103.38 ; \mathrm{p}<0.001$ \\
\hline Intention to stay & 4.46 & 3.52 & $102.72 ; \mathrm{p}<0.001$ \\
\hline Loyalty & 4.44 & 3.54 & $97.03 ; \mathrm{p}<0.001$ \\
\hline Personal sacrifices & 3.88 & 3.38 & $29.19 ; \mathrm{p}<0.001$ \\
\hline
\end{tabular}

At the beginning of the transition to market economy relatively high degree of organizational commitment is established. It is expressed mostly in intention to stay in the organization, which refers to the lack of alternatives for work outside the organization $\left(\bar{x}_{1}=4.46\right)$. Closed nature of socialist economy and tendency for life-time employment in a certain organization determine the high degree of this instrumental component of commitment right after the fall of socialism. Democratization of society and economic crisis in 1990-1997 period strongly influence the willingness of people to stay for a long period on one job position in one and the same organization $\left(\bar{x}_{2}=3.52\right)$. On one hand state organizations reveal their ineffective forms of management and adaptation to changes. On the other, the beginning of private business and the expansion of foreign companies in Bulgaria offer more alternatives for work and people do not feel so "stacked" to the organization any more.

Organizational commitment in 1990, except to economic necessity, is also due to high degree of affective attachment $\left(x_{1}=4.38\right)$. Change in organizations leads to most serious changes in this commitment aspect $\left(x_{2}=3.33, \mathrm{~F}=103.38\right.$, $\mathrm{p}<0.001)$. State organizations are not able affectively to attract and engage their members and to be significant objects for identification, as they did before the change in 1989.

Affective and normative components of organizational commitment are generally most vulnerable to implementation of social and organizational change. Thus, declinations in membership value and loyalty occur organizational membership loses its strength, and loyalty is not the same value any more. High degrees of membership value and loyalty in 1990 can be ascribed to imposed behavior models, which require strict organizational commitment. These results are influenced by the merge of party and organizational membership. Formal requirements and control on organizational membership and on demonstration of loyalty decrease in time.

Personal sacrifices, concerning leaving the organization, have lowest values in comparison to the rest of commitment aspects. Obviously both in 1990 and 1997 organizations do not offer fair payment, adequate work conditions and social recognition and respect and therefore, loses from leave are not perceived as big. 
Dynamics of organizational commitment in the process of transition is characterized by a significant decrease. Organizations are different - they are not what they were in the end of socialism any more and do not form strong commitment as they did before. Environmental changes have deeply influenced the organizational identification and loyalty. State organizations in the process of transformation fail in establishing effective mechanisms for personnel attraction and retention, which to reflect the new social and economic reality. A deep crisis in affective, as well as in instrumental aspects of commitment is observed.

Despite declinations in commitment, reasons for work in organization and organizational identification, stay relatively invariable. Intention to stay due to lack of more favorable alternatives and loyalty are the main reasons for organizational commitment in both time periods. Affective attachment is an important commitment characteristic right after the change in 1989. Difficulties in realization of organizational transformation however determine the deep negative changes in organizational attachment.

\section{Changes in job involvement}

Job involvement has more specific dynamics than organizational commitment (Table 2). A tendency to decrease of all aspects of commitment in the process of transition to market economy. is observed Changes in the two dimensions of job involvement are different.

Job identification changes, though slightly, in positive direction. This tendency however is not statistically significant. Despite the worsening of social-economic conditions and of quality of life, work continues to be the main area of self-realization. This result confirms the view that work importance is slightly influenced by environmental changes. Job identification is determined on one hand by personal factors, as for instance intrinsic work motivation, and on the other - by prevailing work ethics, which is internalized in the process of socialization in a society (Lodahl, Kejner, 1965; Kanungo, 1982). Hence, the seven-year period of transition is relatively short for significant changes in work values to occur and for socialization models to change.

Ego-involvement in work decreases in the process of transition to market economy. There are significant declinations in the degree people aim at exerting efforts in their work. Hence, work is not such a significant source of self-esteem any more and efforts are put in other life areas.

Table 2. Changes in job involvement (means and F)

\begin{tabular}{|l|c|c|c|}
\hline Job Involvement & $\bar{x}_{1}-$ & $\bar{x}_{2}-$ & F \\
& 1990 & 1997 & \\
\hline
\end{tabular}




\begin{tabular}{|l|l|l|l|}
\hline Identification with job & 3.46 & 3.54 & \\
\hline Ego-involvement in work & 3.58 & 3.00 & $155.08 ; \mathrm{p}<0.001$ \\
\hline
\end{tabular}

Work is found to keep its high personal importance and people proceed identifying with it. On the other hand, unfavorable environmental changes and failure of state organizations to restructure demotivate and worsen work engagement and putting efforts in work. Thus, there is no work alienation, but organizations fail to motivate effectively their members and to direct their efforts to achievement of organizational goals.

\section{Changes in work satisfaction}

In the studied periods changes in different aspects in work satisfaction occur as well (Table 3). Unlike the general decrease tendency, typical for commitment and involvement, here the opposite regularity is observed satisfaction increases. Statistically significant changes are registered in all aspects of satisfaction, except satisfaction of colleagues, which is the only constant in time. Positive changes occur in satisfaction of work content, working conditions, supervision, payment and in overall satisfaction.

Table 3. Changes in work satisfaction (means and F)

\begin{tabular}{|l|c|c|c|}
\hline Work Satisfaction & $\begin{array}{c}\bar{x}_{1}- \\
\mathbf{1 9 9 0}\end{array}$ & $\begin{array}{c}\bar{x}_{2}- \\
\mathbf{1 9 9 7}\end{array}$ & F \\
\hline Work content & 3.03 & 3.28 & $27.28 ; \mathrm{p}<0.001$ \\
\hline Working conditions & 2.72 & 3.08 & $36.60 ; \mathrm{p}<0.001$ \\
\hline Colleagues & 3.32 & 3.29 & \\
\hline Supervision & 2.68 & 3.13 & $41.92 ; \mathrm{p}<0.001$ \\
\hline Pay & 2.10 & 2.37 & $13.04 ; \mathrm{p}<0.001$ \\
\hline Overall satisfaction & 3.15 & 3.40 & $18.11 ; \mathrm{p}<0.001$ \\
\hline
\end{tabular}

Unfavorable environmental changes obviously fail to effect work content satisfaction, which keeps relatively high values in comparison to the other satisfaction aspects. Dissatisfaction of payment is characteristic for the beginning of the transition, as well as for the process of change.

Evaluation of the overall work satisfaction has higher values than the specific satisfaction aspects. Hence, despite the worse quality of working life, people are more satisfied with their work, although they are unpleased with their 
work situation. High level of overall work satisfaction shows that work is valuable for people and work alienation has not occurred.

\section{Conclusions}

The main conclusion of this study can be summarized as follows. Our hypothesis for different changes in satisfaction, involvement and commitment is confirmed. Work identification is not liable to significant changes. Despite the vicissitudes of circumstances, work keeps its personal importance constant. However, ego-involvement and organizational commitment decrease in time, work satisfaction increases.

Hence, the transition to market economy is characterized by psychological withdrawal from organizations. The closed nature of socialist economy and central planning did not allow declinations and decrease in organizational commitment to be established before 1989. Till then organizational commitment had not been doubted for ideological reasons and a number of other environmental restrictions.

At present loyalty is not a value any more, as it was for the previous generations. Nowadays people feel no moral obligation to stay in organization. Crisis in commitment is caused by the increase mobility of labor force and by the change in work values. Decrease in the degree and forms of organizational commitment is a result of the opening of organizations to external environment and of the influence of a humanistic approach to people. Organizations are not closed systems any longer, based only on rationality and economic reasons. They become open social systems, where not only material resources, but also people with their motives, needs and attitudes, are significant for the success. This crisis in commitment refers to the crisis in bureaucratic form of state organizations. It leads to the necessity certain interventions for retention of personnel, as well as for increase of its effectiveness and satisfaction, to be undertaken.

Despite the tendency for alienation from organization as a social institution, commitment continues to have higher values than involvement and satisfaction and a leading role in people's work behavior. Therefore, organizations remain significant objects of personal identification, despite the difficulties they have in the process of survival and restructuring.

Deep structural changes in organizations set the problems for management skills/talent and the participation in change. People with their expectations, objectives, needs, motives and attitudes turn into that exceptional factor that determines the success or failure of organizational changes. From this point of view maintenance of high organizational commitment, job involvement and work satisfaction is a criterion for the success of change, as well as for organizational efficiency. 
Possible implications of the obtained results in management practice primarily concern the degree work attitudes can be effected. Undoubtedly, it is much easier to change technology, structure and personnel management systems. These changes not always lead to the expected direct effects on work attitudes and behavior. Thus, organizational change is not implemented completely, because there is no congruence in structure and strategy on one hand and organizational culture with its complex of values, beliefs and attitudes on the other.

The deepest discrepancy between structure, strategy and culture is observed in state organizations, which are in collapse and mostly need transformation. Unfortunately namely in these organization little attention is paid to the impact of changes in internal and external organizational environment on attitudes, behavior and efficiency. Organizations cannot use previous mechanism for attraction, retention and stimulation of personnel any longer, since these old methods have proved their inadequacy in the changed situation. New management practices, which take into consideration dynamics of work attitudes, different speed and depth of their change, are necessary.

Management of organizational change in the process of restructuring and privatization would be more successful if general regularities of work attitudes in transition are considered. Hence, the influence on work identification and its importance in human life is an attitude, which can not be controlled by management. It is not directly effected by environmental factors and its changes can occur in certain generations. Ego-involvement in work can comparatively easier be influenced. Change factors worsen this job involvement dimension and therefore, motivating conditions are necessary to give personal meaning of work in organization.

Work satisfaction changes most quickly under the influence of situational factors and consequently it can be comparatively easy directed and controlled in the desired direction. Satisfaction can increase as a result of technostructural interventions, meant to change certain environmental factors or work content. Increase of satisfaction of work situation aspects and of overall satisfaction is the fastest and direct indicator for the efficiency of organizational change.

Organizational commitment is a result of the complex exchange between person and organization and hence its positive changes require continuous efforts from management. This attitude however predicts behavior and efficiency more successfully than work satisfaction. Increase in commitment requires change in the entire organizational politics to organizational members. That supposes new adequate mechanisms for attraction, selection and replacement of personnel to be developed in order higher degree of congruence between personal and organizational objectives and values to be provided. Implementation of methods for organizational socialization is 
another possible direction for increase of both affective and continuance commitment. In the process of organizational socialization and adaptation organizational culture is conveyed, organizational values are accepted and behavior patterns are learned. Organizational change is not effective if carried out in a random and unpredictable way, without consideration of people's values and attitudes. From this point of view implementation of new approaches of human resource management is a requirement for the success of change, as well as for organizational efficiency.

\section{References}

Angle, H., Perry, J. (1981). An empirical assessment of organizational commitment and organizational effectiveness. Administrative Science Quarterly, 26: 1-14.

Becker, H. (1960). Notes of the concept of commitment. American Journal of Sociology, 66: 32-40.

Buchanan, B. (1974). Building organizational commitment: The socialization of managers in work organizations. Administrative Science Quarterly, 19: 533-546.

Kanungo, R. (1982). Work alienation: An integrative approach. Praeger, N.Y.

Lewin, K. (1951). Field theory in social science. Harper \& Row, N.Y.

Locke, E. (1976). The nature and causes of job satisfaction. In: Handbook of Industrial and Organizational Psychology. Dunnette, M. (Ed), New York, 1297-1342.

Lodahl, T., Kejner, M. (1965). The definition and measurement of job involvement. Journal of Applied Psychology, 49: 24-33.

McGee, G., Ford, R. (1987). Two (or more) dimensions of organizational commitment: Reexamination of affective and continuance commitment scales. Journal of Applied Psychology, 72: 638-642.

Meyer, J., Allen, N. (1990). The measurement and antecedents of affective, continuance and normative commitment to the organization. Journal of Occupational Psychology, 63: 1-18.

Meyer, J., Allen, N., Gellalty, I. (1990). Affective and continuance commitment to the Organization. Evaluation of measures and analysis of concurrent and time-lagged relations. Journal of Applied Psychology, 75, 710-718.

Mottaz, C. (1987). An analysis of the relationship between work satisfaction and organizational commitment. The Sociological Quarterly, 28: 541-558.

Mowday, R., Porter, L., Steers, R. (1982). Employee-organization linkages: Psychology of commitment, absenteeism and turnover. New York.

Porter, L., Steers, R., Mowday, R., Boulian, P. (1974). Organizational commitment, job satisfaction, and turnover among psychiatric technicians. Journal of Applied Psychology, 59, 603-609.

Rabinobitz, S., Hall, D. (1977). Organizational research of job involvement. Psychological Bulletin, 84: 265-288. 
Smith, P., Kendall, L., Hulin, C. (1969). The measurement of satisfaction in work and retirement: A strategy for the study of attitudes. Chicago: Rand McNally.

Wiener, Y. (1982). Commitment in organizations: A normative view. Academy of Management Review. 7: 418-428. 